\title{
Frontier Methodology to fix Quality goals in Electrical Energy Distribution Companies
}

\author{
R. Ramirez ${ }^{1}$, A. Sudrià ${ }^{2}$, A. Sumper ${ }^{3}$, J.Bergas ${ }^{4}$, R.Villafáfila ${ }^{5}$ \\ 1-2-3-4-5 - CITCEA - UPC \\ UPC., Universidad Politécnica de Cataluña \\ , Barcelona (España) \\ Phone/Fax number:+0034 934016727, e-mail: ramírez@citcea.upc.edu ; \\ sumper@citcea.upc.edu;sudria@citcea.upc.edu
}

\begin{abstract}
It is necessary to have tools that allow the regulator, or the distributor, to fix the goals of quality according to the electrical system of the area, taking care about the special characteristics that every distribution company has in front of the others. The methodology that this article presents allows having a simple tool to make this comparison and to fix the goals of quality in a possible horizon.
\end{abstract}

Index Terms: DEA, Quality, Electrical Energy distribution, TIEPI, NIEPI.

\section{INTRODUCTION}

Electrical Distribution Companies have the responsibility of bringing the electrical energy to their customers under some criteria of quality established by the market or the regulator. The quality, from the point of view of the customer, is related to technical aspects as the continuity and the waveform of the electrical energy that is received. The quality perceived like this, is being converted in a decisive parameter in the negotiation of bilateral contracts in the not regulated market and in factor of penalty in the tariffs of the regulated market of the electrical energy.

On the other hand, in the last years it has been increased the need to count with mechanisms that allow the quantification, from the regulative point of view, of what is recognized as a bad energy quality and to achieve that the effects are reflected in the tariffs. It is for this necessity that this variable has been involved in the schemas of tariffs of the regulated market and in the ones called of remuneration by incentives.

The schemas of Regulation for incentives have been used with success in different types of public companies and in private companies devoted on the production of goods and services.

The quality turns into a definite variable in the calculation of the retribution for incentives. For its use, is required the value of the current efficiency and/or the value of the goal that is wanted to reach. Fixing the goals of these values is converted in a complex process and many times subjective, that responds to arbitrary or empirical criteria of the regulator.

This document presents the application of the methodology of surrounding analysis of data (Dates Envelopment Analysis) that is involved with the so- called border methods to obtain the goals of quality for a group of electrical companies.

\section{THE QUALITY AND REGULATION OF THE DISTRIBUTION COMPANIES}

There are several levels of quality, depending on the activity that the distribution company develops and its relationship with the customer:

- Commercial quality: It is the one perceived by the customer and comprises the quality of the customer service (from the point of view of the electrical company) and the activities related with the measurement and payment of the energy.

- Technical quality: It corresponds to the quality related with the continuity and to the waveform of received energy.

In the commercial quality, it is possible to distinguish between the transactions that are carried out before establishing the supply, as it could be for example the access to the network, the development of the connections to the distribution network, the establishment of the power that it is wanted to hire, the installation of the electricity meter can be differentiated etc. and the actions that are carried out during the development of the contract as they are the invoicing, the attention to the customer, the reading of the electricity meters, etc.

The commercial quality, from the customer point of view, takes care about the reliability of the electrical installation and the level of compatibility of the devices and the machines with the electrical energy received from the company. In any case, the regulating organism must look for minimizing the actions that damage the good quality of electrical energy distribution as well as fixing limits or goals of these indexes of quality. It must also fix the penalty for those that are below the fixed limits.

There are parameters related with the technical quality, as for example, the continuity of the supply and the quality of electrical wave. In the case of this article, the quality will only be analyzed from the point of view of the continuity of supply, because until now it is the one that has a most active regulation and the one that counts with greater available information. It is necessary to indicate that the methodology presented can be useful to evaluate other variables of quality, as the waveform, but it is necessary to have complete information about the involved variable. 
Quality indicators that were taken into account in the development of this article were: TIEPI (Installed Capacity interrupted by the hours interrupted/ Installed Capacity) and the NIEPI (Installed Capacity interrupted/ installed capacity)

\section{DATA ANALYSIS DEA}

ENVELOPMENT

The DEA is one of the called border methods and corresponds to a technique of linear programming, which measures the efficiency of a company regarding to several possibilities of production, this group of production possibilities is built by stretches, following the observations of the other companies of the sector. The border methods are developed from the principle of the Benchmarking.

In general, the Data Envelopment Analysis, or surrounding Analysis of data, is a technique of mathematical programming introduced firstly by Charles, Cooper and Rhodes (1978), which allows to calculate the index of technical efficiency solving a mathematical program of optimization. The DEA suggests developing a linear program for every productive unit. In the case of the distribution of electrical energy, every productive unit would be a distribution company, however, and as it will be commented further, some distribution companies have presence in provinces regions completely different. In this case, it is necessary to define sectorizations that allow the information processing.

The DEA allows, through observations of the production of a group of units (DMU), to measure the limit of productivity of the process across a border. The determination of the frontier can be done through a function of costs or a production function. The first shows the total cost of the production as a function of the level of product and the price of the resources. The second shows the quantities produced as a function of the used resources.

In a primary analysis, the public companies do not look for minimizing the production; on the contrary, they look for minimizing costs increasing to the maximum the production, what will be converted in sales. On the other hand the regulator intends to fix a minimum level of efficiency, guaranteeing some supply conditions, where the demand is the first to be satisfied.

In the Figure 1, the DEA methodology is described for a simple example of two resources $(\mathrm{x} 1, \mathrm{x} 2)$ and a product (Y), the drawn isoquant shows the production border; a point to the right of the graph means that there is the possibility to have a different linear combination that produces the same quantity of product in a more efficient way. In fact, this linear combination on the isoquant is more optimum than the one of the point to the right. According to Farrel, the measurement of the inefficiency is determined as the reason of OP/OC.

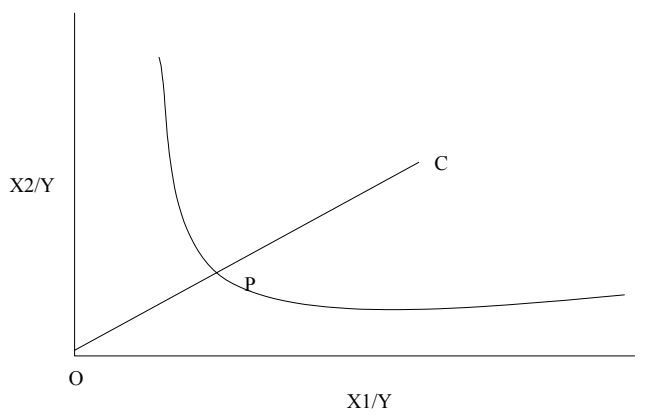

Fig. 1. DATA ENVELOPMENT ANALISYS

\section{DEA METODOLOGY DEA TO COMPARE THE QUALITY IN DISTRIBUTION}

The DEA methodology can be expressed in the following Steps:

1. describing the properties of the production technology, through a set of suppositions. In general, the variables that determine the productive process or that are going to be valued in the exercise. The plans that are associated to theses variables must be established. In the case of distribution companies, must be verified which are the variables that affect to the quality in the service: length, number of customers, installed capacity, investments, time of failures, etc.

2. Next, the type of index whose value is wanted to estimate must be defined. In case of distribution companies, the continuity of supply has been established as criterion through the indicators of TIEPI and NIEPI.

3. Then, a mathematical program that allows calculating the index specificated in the step 2, is built.

The methodology of optimization suggested for the case of the electrical sector, corresponds to a radial method of global technical efficiency measurement (Cooper 2000).

Let's consider a number of 5 DMU in our case, distribution companies ED. Initially, we have only one measurable exit, for every ED: TIEPI - TIEPI, and only one measurable entry (entrance) number of squads or maintenance squads E.

The information that we have of our company is:

$\begin{array}{rll}\text { ED } & \text { TIEPI } & \text { E } \\ 1 & 60 & 4 \\ 2 & 40 & 8 \\ 3 & 20 & 6 \\ 4 & 50 & 3 \\ 5 & 60 & 5\end{array}$

For example the ED1 has a TIEPI of 60 minutes and 4 equipment| of maintenance. A method to compare the efficiency in this case is the indexes or specific gravities. 
These are calculated as the proportion of the exit on the entry

$\begin{array}{llll}\text { ED } & \text { TIEPI } & \text { E } & \text { TIEPI / E } \\ 1 & 60 & 4 & 15 \\ 2 & 40 & 8 & 5 \\ 3 & 20 & 6 & \mathbf{3 . 3} \\ 4 & 50 & 3 & 16.7 \\ 5 & 60 & 5 & 12\end{array}$

In our case, the highest value of efficiency is for ED 3. This complies with greater yields than the rest with 3.3. min./squad.

If it were wanted to compare how much efficient are the rest of the ED in front of the 3, the calculation would be:

\begin{tabular}{|c|c|c|c|}
\hline ED & TIEPI / E & $\%$ & \\
\hline 1 & 15 & $100(3.3 / 15)$ & $22 \%$ \\
\hline 2 & 5 & $100(3.3 / 5,0)$ & $67 \%$ \\
\hline 3 & 3.3 & $100(3.3 / 3.3)$ & $=100 \%$ \\
\hline 4 & 16.7 & $100(3.3 / 16.7)$ & $=20 \%$ \\
\hline 5 & 12 & $100(3.3 / 15)$ & $28 \%$ \\
\hline
\end{tabular}

The obtained values show that the efficiency referred to the ED 3, varies between $20 \%$ and $67 \%$.

Until now a very general case of comparison of efficiency has been evaluated, the reality is that the productive processes, and in this case the quality, have bigger quantity of resources and can be compared by results different to the TIEPI.

An extended example for the same problem is the following one:

$\begin{array}{llll}\text { ED } & \text { TIEPI E } & \text { M€ MES } \\ 1 & 60 & 4 & 10 \\ 2 & 40 & 8 & 12.5 \\ 3 & 20 & 6 & 6 \\ 4 & 50 & 3 & 4.3 \\ 5 & 60 & 5 & 8.2\end{array}$

In this case, the distributing company 3 , has a TIEPI of 20 minutes every month with 6 equipments or squads of repair and an investment of 6000 euros in maintenance every the month.

To measure or to compare the efficiency of these ED, it is necessary to calculate first the ratios or indicators for every case. So, the exits (TIEPI) are divided up in the entries ( $\mathrm{E}$ and $\mathrm{M} €$ )

Then, the indicators can be calculated like this:

$\begin{array}{lcl} & \text { TIEPI/ED } & \text { TIEPI/M€ } \\ 1 & 15.0 & 6.0 \\ 2 & 5.0 & 3.2 \\ 3 & 3.3 & 3.3 \\ 4 & 16.7 & 11.6 \\ 5 & 12.0 & 7.3\end{array}$

It is possible to see that ED 3 has the lowest value of the first indicator (the best), in the case of the second indicative, the highest relation will be looked for, and it will be the value of the ED 4. This type of comparison of the efficiency is then more complex. If the distributing companies 1 and 3 are compared: for example, as for the number of equipments, ED3 will be 15 and 3.3 times more efficient that ED1, but as for the resources 1 will be 6 and 3.3 times more efficient that the 3 . These values can not even be expressed as a unique cipher. The following step is therefore, to look for the way of making it. The problem turns every time more complex as they had a bigger number of ED (exits) and greater number of entries (resources).

\section{GRAPHIC ANALYSIS}

In the case of having two entries and an exit, there can be a graphic solution for the problem of Quality in distribution companies.

In the following graph the values obtained in the previous section can be seen. Mathematically, the efficiency border is the convex area that groups together the data.

The efficiency border determines that any company of electrical distribution can look for arriving to the border, achieving more efficiency this way.

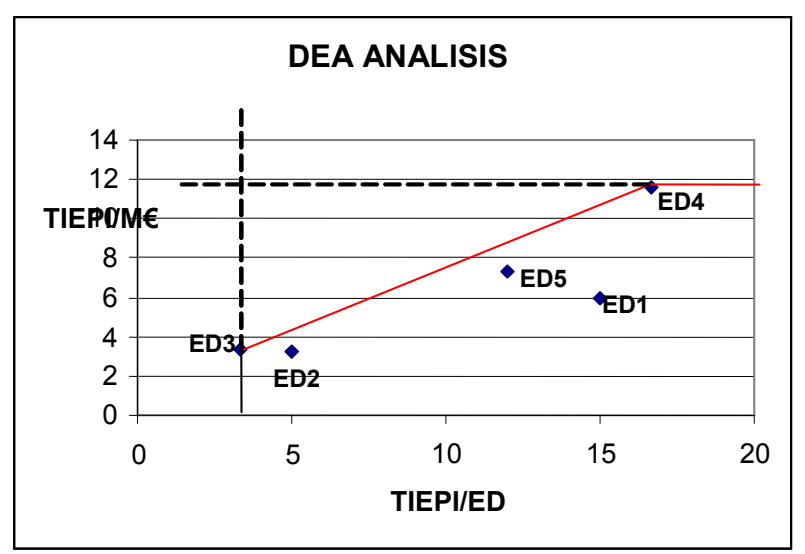

Fig. 2. Graphic Analysis

With this information, it is possible to do the Surrounding Analysis of Data. The convex efficient frontier contains all the results obtained (Fig. 2). It can be said that any ED on the efficiency border is $100 \%$ efficient (it has an efficiency of 100\%). For our example, D3 and D4 are $100 \%$ efficient, but this does not mean that the yield of D3 and D4 can not be surpassed.

From the analysis, it can be obtained:

- The DEA only measures relative efficiencies. It only considers relative efficiencies. It does not give and can't even give absolute efficiencies.

- New information has not been used. The information of entry and exit has been taken, presenting it in a particular way. 
- It is also necessary to notice that an efficiency of $100 \%$ is really strange, and it is not logical to think that an ED has such levels of efficiency.

\section{QUANTIFICATION OF EFFICIENCY FOR UNEFFICIENT DMU' $S$.}

In our example ED1, ED2 and ED5 have smaller efficiencies, if the other two (ED3 and ED4) have efficiencies of $100 \%$, it is necessary to quantify how much efficient are the others (FIGURE 2.).

The goals or benchmarking for each of the ED can be calculated to be efficient. Graphically it corresponds to draw a line from the origin up to the corresponding ED. The cut point with the efficiency border of efficiency determines the value which must be reached to have the border efficiency or limit of the group of ED.

The use of diagrams to determine efficiencies is easy to understand but it is limited to the quantity and quality of information that gets involved in the stage of efficiency. The interpretation of the information as well as the measurement of the ratios or indexes of efficiency is a key issue in the development of the theory.

In the case of quality in distribution companies, with the information that is being handled, the way of achieving the efficiency frontiers is either to decrease the squads or groups of maintenance or to raise the effectiveness of them looking for greater productivity for investment.

An additional important point is the meaning of the relative efficiency, in this sense any variance in the ciphers of any of the ED can vary the analysis of all the company, likewise, and the inclusion of a new ED can mean a new order of efficiency.

\section{ANALYSIS EXTENDED FROM THE METHODOLOGY}

Up to this moment, the analysis that has been carried out shows that the graphic development is possible for an entry and two products, or for two entries and a product. It is impossible to develop graphic analyses with more than two entries. So, we are going to develop the methodology for the resolution of complete systems.

Conditions for the development of a DEA methodology:

1. It is required to have information of all the input and output data for every DMU, in this case ED specified.

2. The efficiency is defined for every DMU as the addition of the weights of the output data, divided up by the addition of the weights of the inputs.
3. All the efficiencies are measured between one and zero.

4. In the development of the calculations of the numerical values for the efficiency of a unit DMU, the weights are maximized

For the case of the distribution companies' example, to calculate the efficiency of the company ED2 the mathematical notation would be:

Max. ED2

Subjected to:

$$
\begin{aligned}
& \mathrm{EED} 1=(4 * \mathrm{We}+60 \mathrm{Wm} €) /(10 \mathrm{WTIEPI}) \\
& \mathrm{EED} 2=(8 * \mathrm{We}+12.5 \mathrm{Wm} €) /(40 \mathrm{WTIEPI}) \\
& \mathrm{EED} 3=(6 * \mathrm{We}+6 \mathrm{Wm} €) /(20 \mathrm{WTIEPI}) \\
& \mathrm{EED} 4=(3 * \mathrm{We}+4.3 \mathrm{Wm} €) /(50 \mathrm{WTIEPI}) \\
& \mathrm{EED} 5=(5 * \mathrm{We}+8.2 \mathrm{Wm} €) /(60 \mathrm{WTIEPI})
\end{aligned}
$$

$$
\text { We, Wm€,WTIEPI }>=0
$$

EEDi= Distribution company's efficiency and We, Wm€,

WTIEPI $=$ Weights of the inputs and the outputs respectively.

For the calculation of the another ED's efficiency, it is enough to vary the function to optimize. As it can be seen, the weights of the variables of input or output must be higherr than zero.

The problem as it is expressed is not a linear problem; therefore it is necessary to make it linear.

To convert the problem to a linear problem, it is necessary to do:

1. The restrictions are replaced, leaving the problem in terms of the weights. The variables $\mathrm{E}$ disappear.

2. An additional restriction is introduced so that the denominator of the objective function is equal to 1 .

Making these changes, the problem is reduced to:

Maximize $(8 * \mathrm{We}+12.5 \mathrm{Wm} €) /(40 \mathrm{WTIEPI})$

Subjected to:

$$
(40 \text { WTIEPI })=1
$$

$0<=(4 * \mathrm{We}+60 \mathrm{Wm} €) /(10 \mathrm{WTIEPI})<=1$

$0<=(8 * \mathrm{We}+12.5 \mathrm{Wm} €) /(40 \mathrm{WTIEPI})<=1$

$0<=(6 * \mathrm{We}+6 \mathrm{Wm} €) /(20 \mathrm{WTIEPI})<=1$

$0<=(3 * \mathrm{We}+4.3 \mathrm{Wm} €) /(50 \mathrm{WTIEPI})<=1$

$0<=\left(5^{*} \mathrm{We}+8.2 \mathrm{Wm} €\right) /(60 \mathrm{WTIEPI})<=1$ 


$$
\text { We, Wm€,WTIEPI }>=0
$$

As the value of 40 WTIEPI $=1$ is replaced in the function to optimize as well as in the restrictions, the problem is converted then in linear

A general formulation of Efficiency is defined as:

$$
h=\frac{\sum_{k} v_{k} * y_{k}}{\sum_{j} u_{j} * x_{j}}
$$

If "x" and " $y "$ correspond to the resources and the products, respectively, the value of $\mathrm{v}_{\mathrm{k}}$ is the weight value of a vector of products and $u_{j}$ the weight value of the impucts.

The $\mathrm{k}$ subscript is referred to every DMU (in our case every distribution company), the $\mathrm{j}$ subscript refers to the resources.

The problem of optimization is:

$$
\begin{aligned}
& \max h_{m}=\frac{\sum_{k} v_{k} y_{k, m}}{\sum_{j} u_{j} x_{j, m}} \\
& \text { S.A. } \\
& \frac{\sum_{k} v_{k} y_{k, m}}{\sum_{j} u_{j} x_{j, m}} \leq 1 ;-i=1, \ldots, I \\
& \sum_{k} v_{k} y_{k, m}=K_{0} \\
& v_{k}, u_{j} \geq 0 ;
\end{aligned}
$$

$h_{m}=$ Efficiency Index of the Evaluated Unit. As it can be seen, is necessary to have an optimization model for every DMU unit, or Distribution Company.

$\mathrm{Y}_{k, m}=$ Quantity of $\mathrm{k}$ product produced for every $\mathrm{m}$ evaluated unit.

$\mathrm{X}_{j, m}=$ Quantity of $\mathrm{j}$ resource consumed for the $\mathrm{m}$ evaluated unit.

$\mathrm{V}_{k}=$ Consideration assigned to the product

$\mathrm{Uj}=$ Consideration assigned to the resource

The problem described in (2) presents the following DUAL:

$$
\begin{aligned}
& \min \frac{1}{M} \sum_{m=1}^{M} \theta_{m} \\
& \text { S.A. } \\
& -y_{m}+\sum_{i} \lambda_{-} y_{k, i} \geq 0 ; \text { para_todo_k } \\
& -\theta_{m} x_{j, m}-\sum_{i} \lambda_{-} x_{j, i} \geq 0 ; \text { para_todo_j } \\
& \lambda_{-i} \geq 0 ; \text { para_todo_i } i
\end{aligned}
$$

The resolution of the DUAL problem presents advantages on the primal. As well as the dual is a linear problem, the values of the $\lambda^{\prime}$ s correspond to values of the shadow price of the restriction on the fundamental problem.

Restrictions in the fundamental problem fixes the $\mathrm{hm}$ value in a cipher smaller that 1 . In the dual, the value of $\lambda$ corresponds to how much lefts to the productive unit to get to be the most efficient lacking. In other words, what is looked for in the dual is the factor that must be applied to the inputs to arrive to the border of production possibilities. In the case of the distribution companies, these values correspond to the "benchmarking" of every distributing company to get to be as efficient as the most efficient of the studied ones.

\section{PROPOSAL OF A MODEL TO COMPARE DISTRIBUTION}

In general, the use of this type of models is limited to the available information. The following variables are suggested in the application of a general model.

$$
\begin{array}{rll}
\checkmark \quad \text { Entrances } \\
& \text { : } & \text { Staff } \\
& \text { Km network /user } \\
& \text { : } & \text { Investment } \\
& \text { : } & \text { Exit } \\
\checkmark \quad \text { Exits } & \\
: & \text { TIEPI } \\
: & \text { NIEPI } \\
& \text { CAIDI }
\end{array}
$$

\section{FUTURE DEVELOPMENTS}

The DEA methodology is applicable in different aspects related with the regulation of the distribution companies. Related aspects with the fixation of the retribution, goals of growth, comparison of quality and relative efficiency, can be studied under the optics of this methodology.

So it is necessary to count on the necessary information. The degree of disintegration and the quality and quantity of information determine the veracity of the results.

\section{CONCLUSIONS}

The use of the DEA methodology allows establishing measurements of productivity in distribution companies and doing a comparison between them.

Depending on the available information, more or less deep comparisons can be done among different companies.

The DEA methodology not only allows to identify which is the value of the relative efficiency among companies, also allows to determine as much as they have to vary the inefficient provinces to achieve efficiencies comparable to the others, (parameter $\lambda$ ). 
It is necessary for this to have the necessary information. The degree of disintegration, the quality and quantity of information determine the veracity of the results.

The values can give information to the regulator or to the company, to do recommendations or to take decisions related with technician-economical parameters, which can affect the efficiency of the company or province.

\section{REFERENCES}

[1] Charles, Cooper Rodes;

[2] Ramírez R, Sumper. Et al.

[3] T.G. Weyman - Jones; Stochastic Non-parametric Efficiency Measurement and Yardstick Competition in Electricity Regulation;2002.

[4] M. Filippini J. Wild; Yardstick Regulation of Electricity Distribution Utilities Based on the Estimation of an Average Cost Function; 22nd, IAEE annual International Conference; New Equilibrium in thr energy markets: The role of new regions and areas; 1999.

[5] V.B. Antequera M.; La remuneración de la Actividad de la Distribución de Energía Eléctrica. El proceso de Liquidación; Trabajo de Curso; 2001. 